\title{
A CRIAÇÃO DE NOVAS UNIDADES FEDERATIVAS NA AMAZÔNIA E A QUESTÃO AMBIENTAL: O CASO DO ESTA- DO DO AMAZONAS
}

\author{
The creation of new federative units in Amazônia and the \\ environmental question: the case of Amazonas State
}

\author{
Adnilson de Almeida SILVA ${ }^{1}$ \\ Wendell Teles de LIMA ${ }^{2}$ \\ Gustavo Henrique de Abreu SILVA ${ }^{3}$ \\ Josué da Costa SILVA ${ }^{4}$
}

\begin{abstract}
RESUMO
Este artigo propõe discutir a idéia atual de divisão territorial do Estado do Amazonas, a qual implicará na criação de três Territórios Federais, a saber: Rio Negro, Solimões e Juruá, cuja concepção de alguns segmentos da sociedade organizada amazonense, será o de promover o desenvolvimento da região considerada "pobre" devido às distâncias geográficas em relação à capital Manaus - centro dinâmico econômico do Amazonas. A criação dos três territórios no lugar de estados poderá proporcionar, na visão dos militantes políticos e das organizações populares, um incremento de recursos federais, dinamizando a economia regional. No entanto, isso implicará em impactos sociais, econômicos, políticos, culturais e ambientais, sobretudo com pressões sobre as terras indígenas e seus recursos, podendo inclusive reduzi-las, já que muitas ainda não foram devidamente regularizadas pela União. É de conhecimento que essas terras têm um papel importante na preservação dessa porção da Amazônia, sendo que a construção de novas unidades federativas na região é vista como uma nova forma de uso e ocupação do território brasileiro pelas novas estratégias geopolíticas.
\end{abstract}

Palavras-chave: Amazônia; geopolítica; divisão territorial; regionalização.

\begin{abstract}
This paper proposes a discussion over the idea of territorial division of the current state of Amazonas. This process will involve the creation of three federal territories: Rio Negro, Solimões and Juruá, whose idea of some segments of society organized Amazon, will be promoting the development of the region considered "poor" due to geographical distances in relation to Manaus - dynamic economic center of Amazonas. The creation of the three territories instead of states could provide, in view of militant political and popular organizations, an increase of federal resources, boosting the regional economy. However, this will mean social, economic, political, cultural and environmental impacts, especially from the pressures on indigenous land and its resources, and may even reduce them, since many have not yet been properly settled by the Union. It is known that these lands have an important role in the preservation of that portion of the Amazon, and the construction of new Federal units in the region is seen as a new form of using and occupation of Brazilian territory by the new geopolitical strategies.
\end{abstract}

Keywords: Amazon; geopolitics; territorial division; regionalization.

1 Graduado em Geografia. Especialista em Análise Ambiental. Mestre em Geografia pela Fundação Universidade Federal de Rondônia UNIR. Doutorando em Geografia pela Universidade Federal do Paraná - UFPR e pesquisador-colaborador do Núcleo de Estudos em Espaços e Representações - NEER e do Grupo de Estudos e Pesquisas sobre Modos de Vida e Populações Amazônicas - GEP Cultura Amazônica/ UNIR. Bolsista do Programa de Cooperação Acadêmica - PROCAD-Amazônia. E-mail: adnilsonn@hotmail.com

2 Graduado em Geografia. Especialista em Turismo e Gestão Territorial; Mestre em Geografia pela Universidade Federal de RondôniaUNIR; Professor da Universidade Estadual do Amazonas - UEA. E-mail: wendelltelesdelima@hotmail.com

3 Graduado em Geografia. Mestrando em Geografia pela Fundação Universidade Federal de Rondônia. Pesquisador do Grupo de Estudos e Pesquisas sobre Modos de Vida e Populações Amazônicas - GEP Cultura Amazônica/UNIR. E-mail: gustavorepentista@hotmail.com

4 Doutor em Geografia pela Universidade de São Paulo - USP. Professor do Departamento de Geografia e Vice-Coordenador do Mestrado em Geografia da UNIR. Pesquisador do Grupo de Estudos e Pesquisas sobre Modos de Vida e Populações Amazônicas - GEP Cultura Amazônica/UNIR e do Núcleo de Estudos em Espaços e Representações - NEER. E-mail: jcosta@unir.br 


\section{INTRODUÇÃO}

\section{A DIVISÃO TERRITORIAL: BREVE COMENTÁRIO}

Em 1997, a "tese" da divisão territorial do Amazonas volta a ocupar destaque na mídia local, como panacéia para o desenvolvimento do interior, e das cidades mais distantes da capital manauara, como também da estratégia da concepção geopolítica acerca da ocupação do espaço amazônico.

Os problemas, à vista desta temática, não estão somente ligados ao crescimento econômico dos municípios mais distantes da capital, nem dos ideais geopolíticos de ocupação do território amazônico, aclamado pelos militares, mas também, com as terras indígenas e as unidades de conservação, elementos vitais à proteção do gigantesco patrimônio biológico, que podem sofrer conseqüências através de sua redução territorial ou pressão sobre os seus recursos naturais.

É preciso deixar claro que terras indígenas não são áreas de preservação ambiental, mas o fato de que ambas podem bloquear a fragmentação fundiária, e conseqüentemente os impactos nocivos do uso da terra, inscrevem-nas no campo das políticas territoriais de proteção, como elementos indispensáveis na conservação do patrimônio natural existente nos ecossistemas amazônicos.

\section{A DIVISÃO TERRITORIAL: NOVAS UNIDADES AD- MINISTRATIVAS PARA A AMAZÔNIA}

A atual proposta de divisão e criação de novas unidades administrativas no Estado do Amazonas, o primeiro passo foi dado pelo senador Mozarildo Cavalcante, de Roraima, com modificações do senador Jefferson Perez (PDT/AM), publicado no Diário Oficial da União de 10/11/2000, que substitui a criação do Estado Solimões, na calha do rio de mesmo nome, por três territórios federais, Rio Negro, Solimões, Juruá ${ }^{5}$, como estratégia de impulsionar o desenvolvimento regional.
Aárea a ser desmembrada representa aproximadamente $46 \%$ do território amazonense, ou seja, 719 mil $\mathrm{Km}^{2}$ distribuídos em 23 municípios habitados por 438 mil pessoas, com densidade demográfica de 0,6 hab./ $\mathrm{Km}^{2}$, conforme aponta os dados do Censo de 2000 do IBGE. Sua extensão equivale aos territórios de Alagoas, Amapá, Roraima, Alagoas, Sergipe e Espírito Santo somados. Seria maior do que a Bahia, Minas Gerais, Mato Grosso do Sul, Maranhão ou a França.

O abandono do interior é uma das causas objetivas desse movimento de divisão territorial. A situação econômica de vários municípios do Amazonas junto com a grande extensão territorial do Estado dos municípios mais distantes da capital é colocada como fator decisivo para a divisão. Na concepção de algumas classes sociais organizadas no Estado, a atividade econômica terá uma alavancada com a criação dessas unidades federativas. A "estratégia" na substituição da criação de um Estado por três territórios levaria o Governo Federal a direcionar recursos diretos a estas regiões menos desenvolvidas. Desse modo, o poder central ficaria mais próximo desses municípios criando assim recursos e infra-estruturas necessárias, para esta parte do território do Estado do Amazonas, conforme se vê na proposição dos mapas 1 e 2.

5 Pela proposta de criação dos três territórios federais no Amazonas, a composição seria: a) Rio Negro com os municípios de Barcelos, São Gabriel da Cachoeira e Santa Isabel do Rio Negro; b) Solimões com Alvarães, Amaturá, Atalaia do Norte, Benjamin Constant, Fonte Boa, Japurá, Jutaí, Maraã, Santo Antônio do Içá, São Paulo de Olivença, Tabatinga, Tonantins e Uarini; c) Juruá com Caruari, Envira, Eirunepé, Guajará, Ipixuna, Itamarati e Juruá. 


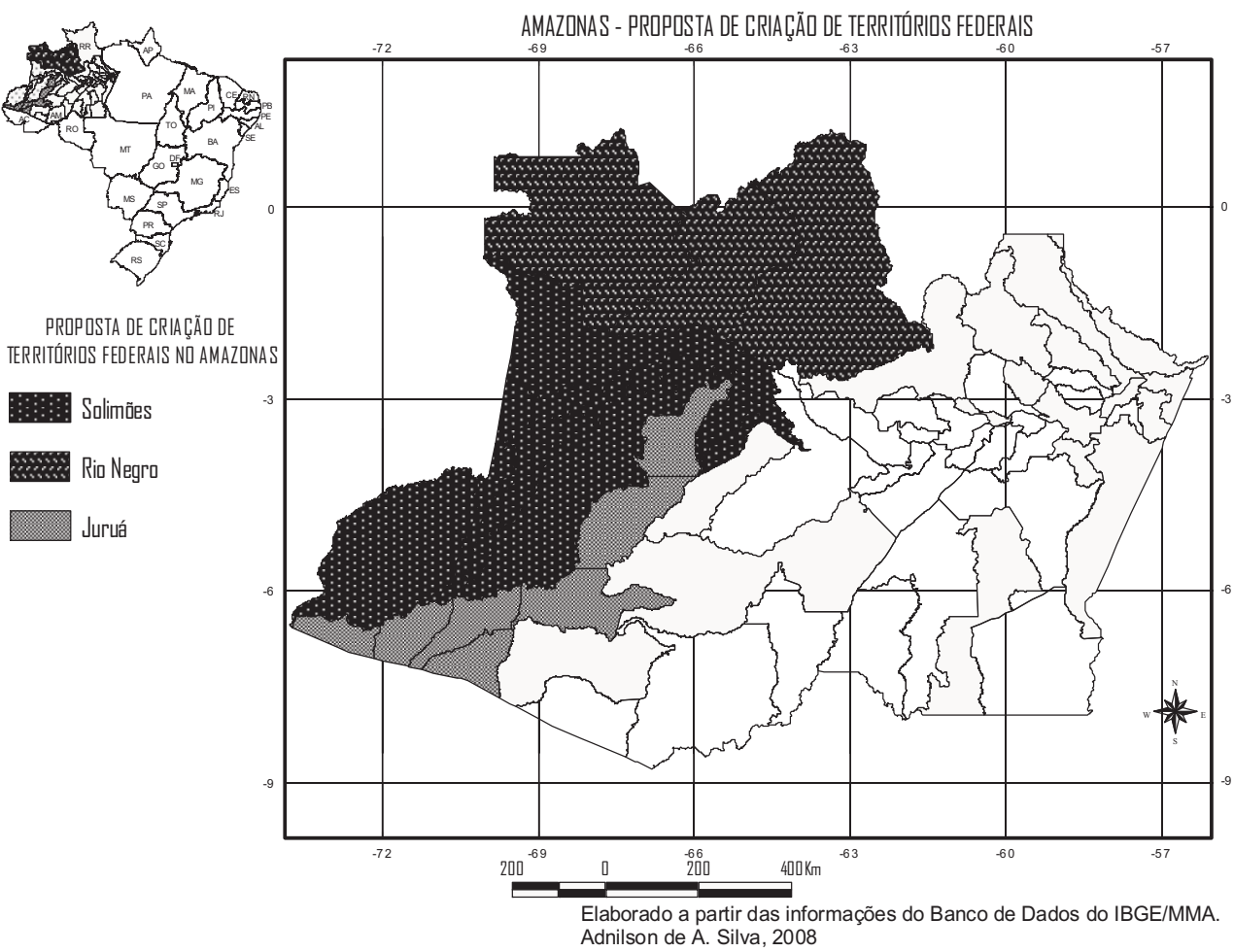

FONTE: Elaborado a partir das informações do Banco de Dados do IBGE/IBAMA. Adnilson de A.Silva, 2008.

MAPA 2 - AMAZONAS - PROPOSTA DE DIVISÃO TERRITORIAL

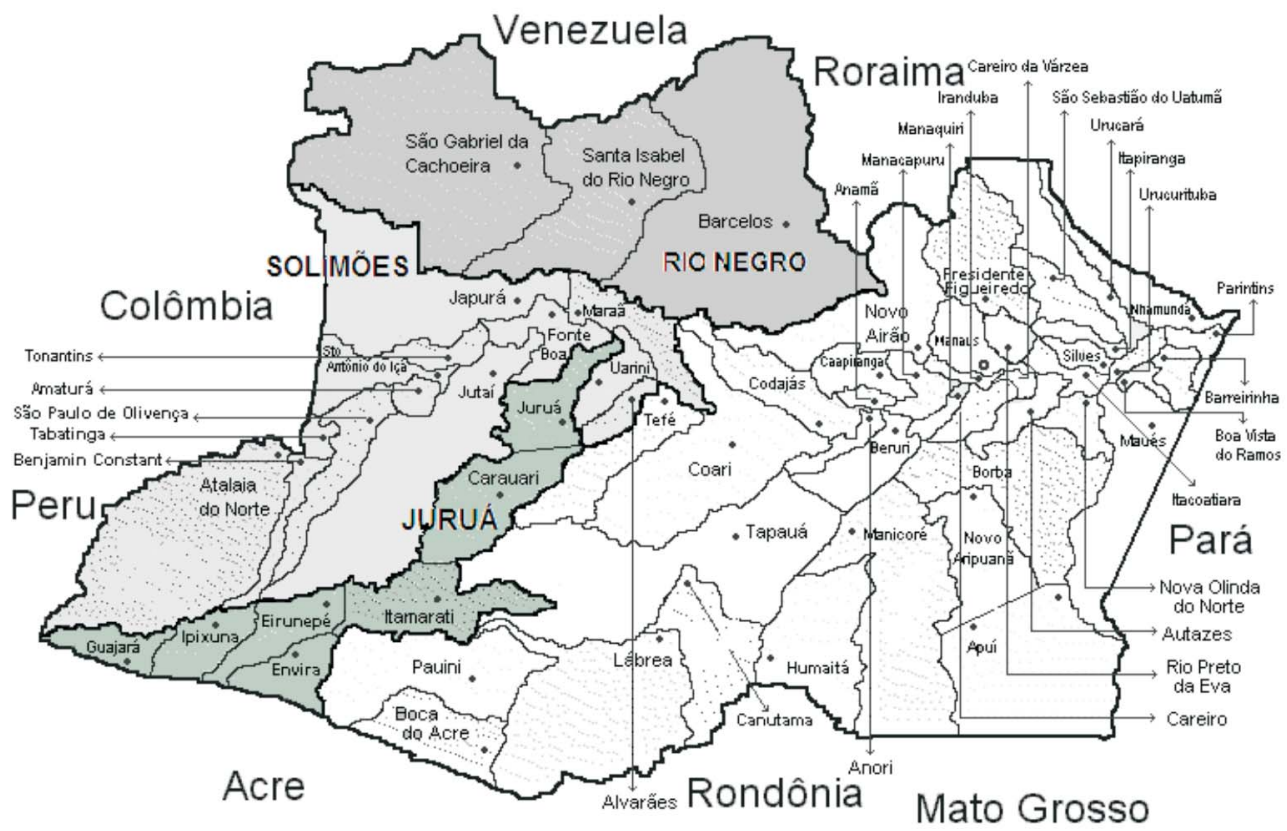

FONTE: Elaborado a partir das informações do Banco de Dados do IBGE/IBAMA. Adnilson de A.Silva, 2008. 
A criação de novas unidades federativas não só na Amazônia como no restante do país é tratada por inúmeros teóricos da geopolítica brasileira como mostra Backheuser (1993) apud Miyamoto (1995, p. 45):

Everardo Backeuser, propondo uma divisão segundo o princípio da equipotência, procurou mostrar a conveniência ser obedecida um conjunto de circunstâncias que serviriam para manter o país unido dentro de um regime federativo. Foi em defesa deste, aliás, que Backeuser com esmero debateu em todos os estudos o desenvolvimento equilibrado de todas as regiões é só o que se aspira, ou, (retire a vírgula) na impossibilidade de sua realização plena, que a divisão mantenha o bloco nacional e sirva para manter a unidade do país. Lembrando-se da existência de estados grandes e pequenos, ricos e pobres, mais ou menos povoados, e do desequilíbrio de poder entre eles, propôs uma divisão que atendia aos seguintes objetivos:

1. por escopo principal a manutenção e a consolidação da unidade nacional;

2. não se subordinar à tradição ou a outros laços que dificultem o objetivo principal, antes, porém devem procurar estabelecê-los em benefício dessa mesma unidade.

E para tanto dever-se-á:

3. formular uma nova divisão, formulando o mapa físico do Brasil sem, de nenhum modo, atender aos atuais limites interestaduais, considerados inexistentes; e 4. procurar fazer os Estados equipotentes tanto no presente como no futuro, equipotentes em área territorial.

Um fato interessante é que, este substitutivo, retornará à situação jurídica dos territórios federais extintos na Constituição de 1988, como foi o caso de Roraima, Amapá e, ainda, Fernando de Noronha, incorporado atualmente à área territorial de Pernambuco. Estes territórios criados no período militar tinham como finalidade proteger a área de fronteira e criar uma atividade econômica ou mesmo incrementá-la. No entanto, isso não aconteceu, o que observamos é uma dependência dos ex-territórios, atuais Estados, perante a União aos quais nem mesmo a atividade econômica foi consolidada.

A questão da divisão territorial do país é abordada na constituinte de 1987 como mostra Andrade (2001, p.15):

A constituinte de 1987 foi palco de pressões das várias regiões que pretendiam formar novos estados, fortalecendo a autonomia regional, como o Juruá, no Amazonas, o Tapajós no Pará, o Tocantins em Goiás, o Santa Cruz, na Bahia o Triângulo Mineiro em Minas Gerais. As pressões dos grandes estados contra um possível desmembramento, as despesas que teriam de ser feitas para a sua instauração e a força da tradição vêm contribuindo para que esses pleitos não tenham sucesso. Só o Tocantins conseguiu a sua elevação à condição de estado na Constituição de 1988.

Outra questão a ser levantada é como ficará, então, a sobrevivência econômica e política destes três territórios onde vemos cada vez mais a diminuição dos recursos disponibilizados aos Estados e Municípios, ou seja, a nação brasileira não tem conseguido oferecer um melhor bem estar sócio-econômico e ambiental, devido a suas próprias limitações e problemas políticoestruturais.

Nesse sentido, o processo de decodificação do comportamento territorial, o entendimento e o comportamento do território tornam-se de fundamental importância na construção de qualquer unidade administrativa, e também no processo de territorialidade dos atores globais onde permeiam a fronteira nacional e utilizam o espaço através das verticalidades. Isso resulta em mecanismos de exclusão de diversas ordens: social, econômica, cultural, dentre outros, dando assim uma seletividade espacial em que a rede vai ter um papel fundamental nessa nova organização de estruturação territorial. É preciso compreender que essas novas configurações territoriais não vão se processar isoladamente no arcabouço espacial. Essas novas configurações terão influência direta na vida social, cultural, econômica e ambiental de grupos humanos. E elas não se processam de forma isolada, mas de forma inter-relacionada, o que nos obriga a repensar essas questões geopolíticas de forma mais aprofundada.

\section{NOVAS GEOPOLÍTICAS}

Uma das questões na constituição de novas unidades políticas em nosso país no caso específico, sobretudo, na Amazônia é o significado geopolítico quanto às fronteiras nacionais, cujo foco de preocupação é a existência e confronto das Forças Armadas Revolucionárias da Colômbia - Exército do Povo (FARCs - EP) onde guerrilham, contra o governo daquele país. Essa organização paramilitar foi criada em 1964 como uma guerillha-revolucionária do Partido Comunista Colombiano. As FARCs são a mais antiga e uma das mais capacitadas e melhores equipadas forças insurgentes do continente sul-americano, inclusive, sendo uma das mais temidas devido o espírito revolucionário. Foi durante a Conferência da Sétima Guerrilha, realizada em 1982 que a denominação Ejército del Pueblo ou Exército do Povo (EP) foi adicionada ao nome oficial do grupo.

Nesse sentido, há certo interesse do segmento 
militar quanto à criação de novas unidades federativas em área de fronteira, ou seja, na concepção das forças armadas traria estabilidade e desenvolvimento e um adensamento populacional para essa região. Aqui lembramos a teoria de adensamento populacional voltada à Amazônia através da implantação de Grandes Projetos, buscando-se assegurar a posse do território brasileiro, uma vez que a região era vista como uma região de vazio demográfico, ou seja, não se considerava nas estatísticas os povos indígenas, seringueiros, ribeirinhos, entre outros. Infelizmente tal fato ainda é algo comum, nos dias atuais, em muitos dos estudos oficiais de contagem da população.

Recolocando parte dessa "visão" histórica, a Amazônia repleta de potencialidades, necessita para muitos analistas, preencher seus imensos vazios, surgindo desse modo, porta-vozes da autonomia ideologicamente identificados com a criação dos territórios federais, em decorrência principalmente, da necessidade de afirmação nacional e do desenvolvimento regional.

Assim, o espaço territorial passa a oferecer novas possibilidades, conforme demonstra, Sylvio Fausto Gil Filho (2004, p. 259) em que

O espaço não é cristalização do fenômeno, mas parte das possibilidades relacionais do mesmo. Sendo assim, construímos imagens do espaço e atribuímos a elas as representações de nossa existência.

Partindo da premissa que o espaço é constituído dessas representações, o interesse nacional motivou no Governo Vargas a edição de decretos para criação dos territórios do Amapá, Rio Branco - atual Estado de Roraima - e Guaporé - atual Rondônia - todos na Amazônia; Ponta Porã - extinto e incorporado ao Mato Grosso do Sul - fronteiriço com o Paraguai; e Iguaçu incorporado à área territorial do Paraná, fronteiriço com a Argentina e o Paraguai.

$\mathrm{Na}$ atual fase que passamos, percebemos empiricamente uma permeabilidade maior das fronteiras nacionais com os pactos de cooperação entre países signatários onde se tenta forçar uma união cada vez maior, uma transposição da fronteira ou certo aumento além do território nacional.

Assim surge o questionamento: será que a militarização da fronteira com os países signatários do Pacto Amazônico que assume maior importância no processo de globalização atual, não seria um ato retrógrado? E mesmo a criação de novas unidades federativas em que sabemos que o capital se instala onde é mais conveniente, ou seja, a criação de novas unidades federativas, por si só, seria capaz de impulsionar o desenvolvimento?
É um caso que merece uma profunda reflexão, e para tanto utilizamos dos postulados de Santos (2001, p. 254), que contextualiza:

Na medida em que, com o mercado chamado global,
cada empresa busca satisfazer nos lugares onde as
respostas aos seus reclamos é mais adequada tal
demanda é errática e o território passa a ter, nas áre-
as atingidas por esse tipo de relações, uma dinâmica
praticamente imprevisível no próprio lugar em que
se exerce é também alienada, já que não precisa ter
correspondência com os interesses da sociedade local
ou nacional. Novas formas de compartimentação do
território ganham relevo e são capazes de impor dis-
torções ao seu comportamento: são as novas caras
da fragmentação territorial.

O processo de combate às forças opostas do governo colombiano ou até mesmo do narcotráfico podem ser atendidas por políticas mais consistentes e permanentes por parte dos Estados Nacionais do Pacto Amazônico. Uma nova realidade se configura na região com a entrada como membro permanente do Mercosul, a vizinha Venezuela, e também é interessante observar uma nova funcionalidade e novo entendimento do Pacto Amazônico para a região.

Perante a estas novas constatações no momento atual insistimos que o entendimento do território é fundamental e ele perpassa além de uma visão estadista, de tal maneira, uma visão que vai além da compreensão do Estado-Nação, onde competem com ele várias forças, e é chamado muitas vezes a se unir com estes novos agentes.

Não podemos esquecer que o território possui um caráter identitário, pois os grupos humanos constroem as suas identidades em relações dialéticas com o território. A nacionalidade do indivíduo, a sua terra natal, são coisas intrínsecas na relação dialética identidade/ território. Dentro dessa perspectiva as representações se apresentam também como fator relevante na decodificação territorial.

Nesse sentido, as visões do Estado assumem caráter de representações, conforme demonstra Salete Kozel (2004, p. 229):

[...] passarão a ser tratadas tanto como produtos como processos, mediando espaço real e os grupos sociais, entre a percepção e prática. Os produtos construídos a partir desses procedimentos se constituirão nas bases para a compreensão e análise das transformações sociais e espaciais.

A reestruturação da fronteira, por exemplo, é uma prova disso onde na realidade há pontos de união 
e não mais de exclusão entre os Estados-Nações. Assim, novas sub-regiões e novos poderes sub-regionais começam a se estruturar em nosso país. AAmazônia é parte integrante dessa nova ordem, a qual é chamada a participar desse processo. A entrada da Venezuela no Mercado Comum do Sul configura, assim, um novo eixo de desenvolvimento e uma saída do nosso país ao Caribe como também, o surgimento de uma nova região, com nova abertura e possibilidade de novos entendimentos sobre as fronteiras brasileiras. Uma nova geopolítica se configura em nosso país, ainda que existam resistências por parte de segmentos militares por razões diversas.

\section{A QUESTÃO AMBIENTAL}

A questão ambiental se torna complexa na criação dos territórios, onde existem várias territorialidades indígenas, conforme fica evidenciado no mapa 2. A preocupação com esses povos começou a ser difundida no final dos anos 1970 . No entanto, grande parte das terras indígenas convive com a falta de demarcação de suas reservas, quanto a isso podemos observar o que constata Diegues (2002, p. 30), que na Amazônia:

[...] A ameaça sobre as formas de apropriação comunitária vem da expansão da grande propriedade rural voltada para agropecuária, das grandes empresas mineradoras, das políticas públicas (áreas naturais protegidas e dos grandes projetos). A situação desses sistemas tradicionais de acesso a espaço e recursos de uso comum começaram a ser ameaçadas com o processo relativamente recente de incorporação desses territórios pela expansão urbana industrial e da fronteira agrícola.

O processo de reconhecimento das terras indígenas é dado pela Fundação Nacional do Índio - FUNAI, órgão responsável pelo Governo Federal. No entanto, observamos problemas de procedimentos de regulamentação de suas terras, que na maioria das vezes ocorrem de forma morosa por parte do poder público.

A terra indígena, na visão do Estado, é um espaço homogêneo, um meio de produção, onde estão distribuídos os recursos naturais. Na concepção indígena, a terra é um mosaico de recursos materiais, morais e espirituais intrínsecos a sua territorialidade, assim em sua visão de mundo não existe a dicotomia ser humano/ natureza tão presente na visão da economia de mercado urbano-capitalista. A questão territorial em seus aspec- tos indígenas além de conter dimensões sociopolíticas, também contém uma ampla dimensão cosmogônica, o que não ocorre na concepção de território do Estado.

Em áreas de ocupação brutal, mas efêmera, como nas áreas de produção de borracha, na Amazônia, exploradas durante meio século a partir de 1870, muitos grupos indígenas conseguiram sobreviver, embora suas áreas territoriais tenham sido gradativamente diminuídas. Existem até hoje, provavelmente, cerca de 50 grupos de índios isolados na Amazônia, que procuram manter seu modo de vida longe da "civilização".

Alguns são descendentes de grupos que já tiveram duras experiências com os outros brasileiros e retornaram à mata. A cada dia, esse isolamento é mais precário, um exemplo disso é o surgimento, em 1985, de índios no Estado de Rondônia: encurralados por desmatamentos e investidas em suas terras, se renderam, aceitando o contato.

Todas as Constituições brasileiras, desde a de 1934, garantem aos índios as terras que eles ocupam. Esta ocupação ficou definida na Constituição de 1988, no artigo 231, parágrafo 1, segundo o qual são terras tradicionalmente ocupadas pelos índios as por eles habitadas em caráter permanente; as utilizadas para suas atividades produtivas; as imprescindíveis à preservação dos recursos ambientais necessários ao seu bem-estar e as necessárias à sua reprodução física e cultural, segundo seus usos, costumes e tradições.

As terras indígenas no Brasil ainda não estão completamente regularizadas, apesar do preceito constitucional que estipulava que o fossem até 1993. Em junho de 1996, das 554 áreas, 148 encontravam-se demarcadas e registradas. Correspondem a um total de cerca de 45 milhões de hectares, ou seja, pouco menos da metade da área total das terras indígenas.

As áreas indígenas encontram-se em diferentes estágios de processos de regularização, tais como: a) a identificar, geralmente associadas a grupos isolados; b) áreas delimitadas; c) demarcadas fisicamente, mas sem homologação e registro. As demarcações são necessárias, mas não suficientes para a proteção das terras indígenas, que sofrem invasões de várias naturezas, como de empresas mineradoras, madeireiras, garimpeiros, fazendeiros, entres outros, provocando inúmeros conflitos. Tanto as terras indígenas, reservas extrativistas e unidades de conservação são importantes para a manutenção da biodiversidade, principalmente na Amazônia, conforme se vê no mapa a seguir: 
MAPA 3 - AMAZONAS: UNIDADES DE CONSERVAÇÃO E TERRAS INDÍGENAS

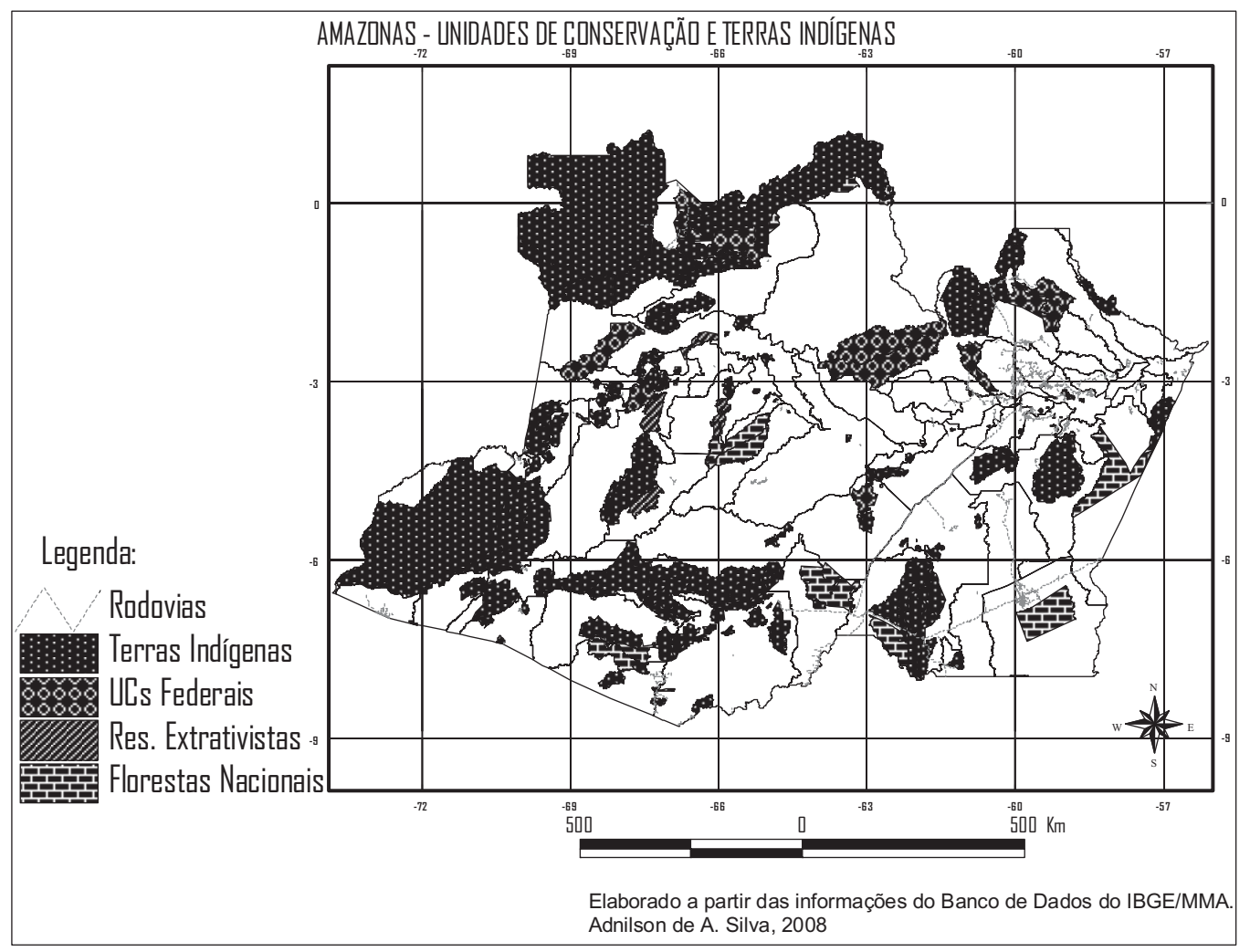

FONTE: Elaborado a partir das informações do Banco de Dados do IBGE/IBAMA. Adnilson de A.Silva, 2008.

No Estado do Ceará, companhias de beneficiamento de coco invadem as terras dos índios Tremembé, e índios Tapeba vivem confinados em um mangue nos arredores de Fortaleza, em uma parcela de sua área. Em várias regiões, as grandes fazendas expulsam agricultores, que por sua vez tornam-se posseiros e invadem as terras indígenas, gerando violência e em muitos casos até chacinas.

Obras de infra-estrutura, como estradas e usinas hidrelétricas - UHEs, também têm colaborado para que ocorra ocupação de parte dessas terras indígenas, criando situações de grandes conflitos, como da região do rio Atumã, onde se construiu a UHE Balbina, provocando alagamento do território dos Waimiri-Atroari.

As estratégias do Estado brasileiro parecem não terminar, para conduzir o processo de territorialidade indígena, um exemplo disso é a tentativa de criação do município de lauarete no noroeste do Amazonas na região conhecida como Cabeça do Cachorro, no Alto Rio Negro, onde a primeira tentativa foi em 1981 e a segunda, em 1989. Ambas foram consideradas pela Procuradoria Geral da República como institucionais, por tratar-se de área indígena em consonância com o art. 31 da Constituição de 1988, que dispõe sobre a inalienabilidade das terras indígenas, não podendo nem mesmo a União delas dispor ou doá-las para municípios.

Por muito tempo se quis impedir ou protelar a demarcação das terras indígenas, com o pretexto de que elas poriam em risco a segurança nacional. Essa tese que acabou sendo refutada com o tempo, pois, ao contrário, o avanço nas medidas de regularização destas terras serviu para assegurar o direito ancestral dos indígenas, para pôr fim a conflitos por posse da terra, os quais muitas vezes se estendiam por décadas, e para garantir a integridade territorial brasileira.

É preciso lembrar que as terras indígenas são patrimônios da União, diversamente da grande quantidade de terras de particulares que estão sendo transferidas para estrangeiros, a exemplo das madeireiras asiáticas. Mais recentemente, alguns segmentos da população brasileira contrários aos direitos indígenas passaram a afirmar que os índios teriam "terras em demasia". Este argumento serve para confundir a opinião pública e reforçar os conflitos com a enorme legião de trabalhadores rurais sem-terras existente no Brasil. 
Acresce-se que as terras devolutas e ocupadas nos padrões dos não-índios são mais do que suficientes para a produção de alimentos requeridos pelo País.

A idéia que se procura propagar com esse tipo de argumentação é a de que, com a regularização das terras indígenas, estar-se-ia reduzindo a quantidade de terras disponíveis para a agricultura e outras atividades econômicas, resultando em escassez de terras para os trabalhadores rurais não-indígenas. Por trás deste argumento agrega-se a crença de que as terras indígenas são improdutivas, o que já está há muito desmentido.

É importante também esclarecer sobre que aspecto a palavra "improdutiva" é muitas vezes utilizada. Sabemos que existe uma concepção de "produtivo" relacionado ao viés econômico, camuflando, assim, questões ambientais e sociais. Registra-se como exemplo que, sendo paralisada a produção indígena, no mercado local da Amazônia Legal haverá, indubitavelmente, fome, mesmo que haja disponibilidade de abastecimento vindo de fora da área. Os custos estariam fora da capacidade financeira da população e as vias de acesso são empecilhos ao pronto abastecimento.

Além disso, estatísticas elaboradas pelo Instituto Nacional de Colonização e Reforma Agrária - INCRA mostraram claramente que, somando-se as terras aproveitáveis e não-exploradas existentes em todos os estados do Brasil, atingiu-se um total de 185 milhões de hectares, o que corresponde, aproximadamente, ao dobro de todas as terras indígenas.

Logo, é a extrema concentração da propriedade fundiária em mãos de poucos membros da sociedade brasileira e sua má ou falta de utilização que levam a larga margem da população rural a não dispor de terras para trabalhar, e não a grande extensão dos territórios indígenas.

Além disso, o montante dos imóveis rurais cadastrados pelo INCRA corresponde a menos de $70 \%$ do território nacional, havendo, ainda, 255 milhões de hectares de terras não-discriminados ou cadastrados pelo Órgão fundiário. Isto significa que, mesmo ressalvando-se as áreas urbanas e aquelas destinadas à proteção ambiental, ao uso das forças armadas, entre outros, resta muita terra para a expansão das atividades econômicas, sem que seja necessário proceder à invasão do habitat das populações indígenas.

Em contrapartida à reivindicação indígena da terra contínua, antes da criação das propostas dos três territórios para o Amazonas, houve o projeto de Decreto Legislativo $n^{\circ} 098$, em 1995, propondo a realização de um plebiscito para a criação do Território Federal do Rio Negro, abrangendo os municípios de São Gabriel da Cachoeira, Santa Isabel do Rio Negro e Barcelos.
A velha estratégia parece que retoma novamente a questão sobre a manutenção das terras indígenas e o não-respeito e reconhecimento desses povos existentes na Amazônia. Com a criação dos três territórios federais propostos poderá levar a uma corrida sem precedentes sobre essas terras que se encontram nessas regiões do Alto Rio Negro, Juruá, Purus e Solimões, a exemplo do que já aconteceu em outras regiões do país.

A pressão pode vir por parte de garimpeiros, posseiros, pelos grandes projetos mineralógicos e pelo setor agrícola, levando até mesmo a uma redução e extinção de algumas etnias. A criação desses territórios, portanto, pode levar até à destruição e devastação da floresta que se encontra conservada.

Essa pressão exercida sobre as terras indígenas tem provocado um processo de violência contínua com a expropriação dos recursos naturais existentes, além da fragmentação da identidade, corroborando com a assertiva de Almeida Silva (2007, p. 75), que conclui:

[...] a violência é decorrente do processo histórico, geopolítico e econômico de ocupação na Amazônia brasileira, estando intimamente ligado às distintas formas e visões de apropriação da natureza, onde as populações indígenas e tradicionais que se encontram no espaço amazônico, milenar e secularmente são protagonistas desse processo, enquanto o conceito de natureza para os detentores do Capital nacional e internacional ou daqueles manipulados por ele (o Capital) é totalmente antagônica em relação àquelas populações.

A tendência que se verifica na região é que à medida que avança o processo de expansão das frentes de ocupação, os conflitos se aceleram, produzindo um efeito devastador e inexoravelmente desfavorável para as populações que há tempos encontram-se assentadas nas florestas e margens dos rios, com isso eliminando valores culturais e ambientais, muitos ainda desconhecidos pela comunidade científica.

\section{CONSIDERAÇÕES FINAIS NÃO CONCLUSIVAS}

As novas unidades administrativas propostas para o Amazonas devem ser entendidas através da estratégia de fatores sociais em criarem suas próprias territorialidades, no entanto, estas podem ter um grau elevado de implicação para a região, pois se permite fazer uma série de questionamentos quanto à sua efetiva viabilidade, tanto social, econômica, cultural, ambiental e política.

Uma das questões de grande relevância diz respeito ao modo como ficarão os recursos orçamentários 
e financeiros para a manutenção desses territórios, onde se verifica que o Estado Nacional, devido as suas peculiaridades, tem enfrentado uma série de problemas quanto à melhoria do bem estar social.

Outra questão, não menos importante, refere-se ao novo entendimento sobre as atuações de fronteiras, frente aos processos de globalização e de integração do continente sul-americano, onde está em implementação a formação de novos recortes territoriais, que implicam em uma maior porosidade sobre as fronteiras, sendo essas concebidas como ponto de união e não mais de exclusão. Assim, as novas estratégias dos atores hegemônicos, no momento atual, levam também a uma reflexão sobre um novo entendimento do território e as estratégias dos atores globais e locais que lutam pelo processo de criação de novas territorialidades, conforme observa Claval (2001, p. 66):

A territorialidade fascina os geógrafos há gerações. O espaço é uma categoria vazia, que não contém qualquer referência à sensibilidade, à recepção, ao sentimento, na vida real atribuem-se muito sentidos aos lugares onde se vive e às pequenas e grandes pátrias. A construção das identidades está intimamente ligada à organização territorial e a maneira como ela é percebida por quem é responsável por essa organização ou a experimenta.

Uma das preocupações que devem ser exaustivamente debatidas e consideradas é em relação ao patrimônio cultural dos povos indígenas, ribeirinhos, entre outros, que poderão ser forçados a se retirar dos seus espaços tradicionalmente ocupados, devido ao pretenso desenvolvimento que se imprimirá com a criação desses territórios.

\section{REFERÊNCIAS}

ALMEIDA SILVA, Adnilson de. Impactos Socioculturais em Populações Indígenas de Rondônia: Estudo da Nação Jupaú. Dissertação de Mestrado. Porto Velho: NCT/PPGG/UNIR, 2007, 255 p.

ANDRADE, M.C. Geopolítica do Brasil. Campinas: Papirus Editora, 2001.

BRASIL. Constituição da República. 1988.

CLAVAL, P.. O papel da nova Geografia Cultural na compreensão da ação humana. In: ROSENDAHL, Z. e CORRÊA, R.L. (orgs). Matrizes da Geografia Cultural. Rio de Janeiro: EDUERJ, 2001.

DIEGUES, A.C.S. O mito da natureza intocada. São Paulo: Contexto, 2000.

FUNAI. Disponível em: <http://www.funai.gov.br>. Acesso em: 20/12/2006.

GIL FILHO, S.F. Por uma geografia do sagrado. In: MENDONÇA, F. e KOZEL, S. (Orgs). Elementos de epistemologia da geografia contemporânea. Curitiba, Ed. UFPR: 2004.

IBGE. Disponível em: <http://www.ibge.gov.br>. Acesso em: 20/12/2006.

INCRA. Disponível em: <http://www.incra.gov.br>. Acesso em: 20/12/2006.

KOZEL, S. As representações no geográfico. In: MENDONÇA, F.; KOZEL, S. (Orgs). Elementos de epistemologia da geografia contemporânea. Curitiba: Ed. UFPR: 2004.

MIYAMOTO, S. Geopolítica e poder no Brasil. Campinas: Papirus, 1995.

SANTOS, M.; MARIA, L.S. O Brasil território e sociedade no início do século XXI. 2. ed. São Paulo: Record, 2001. 
